\title{
Less-Conventional Low-Consumption Galvanic Separated MOSFET-IGBT Gate Drive Supply
}

\author{
Jean Marie Vianney Bikorimana ${ }^{1,2}$ and Alex Van den Bossche ${ }^{3}$ \\ ${ }^{1}$ Ghent University, Ghent, Belgium \\ ${ }^{2}$ University of Rwanda, Butare, Rwanda \\ ${ }^{3}$ Electrical Energy Laboratory, Ghent University, Ghent, Belgium
}

Correspondence should be addressed to Jean Marie Vianney Bikorimana; jeanmarievianney.bikorimana@ugent.be

Received 6 December 2016; Revised 21 February 2017; Accepted 10 April 2017; Published 24 May 2017

Academic Editor: Bor-Ren Lin

Copyright ( 2017 Jean Marie Vianney Bikorimana and Alex Van den Bossche. This is an open access article distributed under the Creative Commons Attribution License, which permits unrestricted use, distribution, and reproduction in any medium, provided the original work is properly cited.

A simple half-bridge, galvanic separated power supply which can be short circuit proof is proposed for gate driver local supplies. The supply is made while hacking a common mode type filter as a transformer, as the transformer shows a good insulation, it has a very low parasitic capacitance between primary and secondary coils, and it is cost-effective. Very low standby losses were observed during lab experiments. This makes it compatible with energy efficient drives and solar inverters.

\section{Introduction}

Many gate driver circuitry designs prefer a galvanic separated gate drive type, but they face the problem of a number of transistors to be driven [1], which ideally would need their own local supplies. The case is even more true in multilevel converters where more drivers are needed.

For the gate driver power supply circuit, a number of issues must be taken into account. Firstly, the power supply must be reliable. Often charge pump or bootstrap circuits have been considered as the best choice for the gate drive power supplies [2]. However, various experiences show that the charge pump does not work in all cases [3]. This is due to the fact that the charge pump/bootstrap circuits can fail while turning off the low side of the inverter for longer time [4]. Moreover, the paper in [5] has demonstrated that the circuits present the weakness vis-à-vis the duty cycle generation mode and range. This can occur as well for the case of the converter that employs the hysteresis control. For the lower transistors, a single supply can generate undesired ground loops by the IGBT's emitter inductance [6].

Secondly, gate drive power supply must be cost-effective. This is usually a business requirement. To minimize the gate drive cost can increase the income benefit on a converter.
This becomes more considered in the case of three-phase or multilevel inverters [7].

Thirdly, the gate driver power supply must not be easily disturbed. The major origin of a disturbance of the gate drive circuit is due to return current injected by high $d v / d t$ during turn-off of the a power device switch [1, 6-14]. The feedback of a small fly back converter may be disturbed by its controlling circuit. The gate drive circuit must be able to overcome it.

Fourthly, the gate drive must have low capacitance [11]. Typical of the shelf block DC-DC power supplies do have a considerable capacitance between the two sides. Often a parasitic capacitor which is in the order of $47-220 \mathrm{pF}$ is embedded in the circuit for the EMI (electromagnetic interference) reduction purpose. Hence, the parasitic capacitance is increased and consequently the power supply can have additional losses. The problem is that the manufacturing companies do not mention this issue in the data sheet, so the circuit developer cannot know how to cope with it. Furthermore, the usage of the DC-DC converters increases the amount of the standby power.

Last but not least, for a long lifetime, designs should avoid electrolytic capacitors, which may reduce the life expectancy [15]. Experience shows that the charge pump solutions often 
need electrolytic capacitors. In the proposed design, this can be avoided.

For the case of gate drive circuit, different factors must be taken into account as well: Most of them are low standby power, undervoltage lockout (UVL) capability, desaturation protection [10,16] feedback signal, and cost effectiveness [17]. Several design philosophies are possible for a stiff power supply which is short circuit proof. A compliant supply can also be used to force a shutdown by an UVLO while using a desaturation protection [16]. The paper focuses more on a design of a less-conventional gate drive supply which can meet the earlier mentioned factors. This can be obtained while using a compliant supply which has some impedance. The compliant supply is made while hacking a common mode type filter as a transformer, as it shows a good insulation and it has a very low parasitic capacitance between primary and secondary coils. The transformer has low consumption and was cost-effectively competitive. The topology, principle of functionality, simulation, and performance test experiment of the gate drive supply are presented in this paper.

\section{The MOSFET-IGBT Gate Drive Supply Principle}

Figure 1 briefly presents the general gate driver block diagram. The optocoupler, HCPL3120, gate drive is powered by a positive voltage delivered by a 15 -volt DC input supply. The PWM controlling signal from a microcontroller is the input of the gate driver. The advantage of the gate driver circuit is that it does need to have a common ground voltage with same gate drive circuit once it is used for a converter with high and low side switches. Figure 2(a) gives more details of the less-conventional, low-consumption galvanic separated MOSFET-IGBT power supply block diagram. The block diagram has three major parts.

This driver has high peak current of $10 \mathrm{~A}$ [13] and an output impedance in the range of $1-3 \mathrm{Ohms}$. Its purpose is to generate an output voltage of $15 \mathrm{~V}, 100 \mathrm{kHz}$ to supply a hacked common mode choke used as a transformer (Figure 2(b)) [12]. It is large enough to supply easily 6 of such transformers. A local supply is made using a peak-to-peak half-bridge Schottky diode rectifier.

Figure 2(a) shows that there are two capacitor legs in the entire topology. One capacitor leg is at the primary side of the transformer and the other one is located at the secondary side. The natural resonance frequency within the total capacitance of $0.44 \mu \mathrm{F}(2 \times 0.22 \mu \mathrm{F}$ ceramic capacitors $)$ at the secondary side resonates with the leakage inductance of the transformer at approximately $44 \mathrm{kHz}$. The measured leakage inductance of the transformer at $1 \mathrm{kHz}$ and $100 \mathrm{kHz}$ is $32 \mu \mathrm{H}$ and $31.16 \mu \mathrm{H}$, respectively. More data concerning the parameters of the transformer can be found in Table 1 .

The operation at $100 \mathrm{kHz}$ is above the series resonance, even if the primary capacitor leg is considered. To smooth the output current and voltage, a $0.22 \mu \mathrm{F}$ film capacitor is added across the output of the half-bridge rectifier; it is also needed for a sufficient charge reservoir to supply the gate. Note that the whole design can be done by using film or

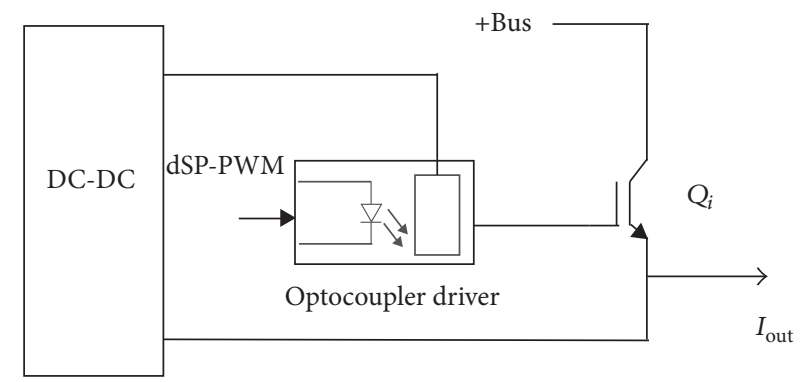

FIGURE 1: MOSFET-IGBT general gate drive circuitry.

TABle 1: Parameters of the transformer common mode filter.

\begin{tabular}{|c|c|}
\hline Parameters & Value \\
\hline Magnetization inductance $(\mathrm{min})^{*}$ & $1 \mathrm{mH}$ \\
\hline Magnetization inductance (measured) ${ }^{* *}$ & $1.6 \mathrm{mH}$ \\
\hline $\begin{array}{l}\text { Insulation between primary and } \\
\text { secondary coils (rms, during } 2 \mathrm{~s})^{* *}\end{array}$ & $2.4 \mathrm{kV}$ \\
\hline Primary secondary coupling capacitor ${ }^{* *}$ & $3 \mathrm{pF}$ \\
\hline Primary turns ${ }^{* *}$ & 43 \\
\hline Secondary turns ${ }^{* *}$ & 43 \\
\hline Rated current $\mathrm{AC}^{*}$ & $0.7 \mathrm{~A}$ \\
\hline Maximum DC resistance (line) ${ }^{*}$ & $0.6 \Omega$ \\
\hline Rise temperature $^{*}$ & $40 \mathrm{~K}$ \\
\hline Weight* & $3.5 \mathrm{~g}$ \\
\hline Short circuit L-R impedance at $1 \mathrm{KHZ}^{* *}$ & $32 \mu \mathrm{H} 1.017 \Omega$ \\
\hline Short circuit L-R impedance at $100 \mathrm{kHz}^{* *}$ & $31.16 \mu \mathrm{H}, 0.86 \Omega$ \\
\hline Foot print ${ }^{*}$ & $10 \times 14 \mathrm{~mm}$ \\
\hline Pin distances size* & $7 \mathrm{~mm} \times 8 \mathrm{~mm}$ \\
\hline Core cross sections ${ }^{*}$ & $3.0 \mathrm{~mm} \times 3.0 \mathrm{~mm}$ \\
\hline Apparent permeability ${ }^{* *}$ & 2753 \\
\hline $\mathrm{Al}^{* *}$ & $865 \mathrm{nH} /$ turn $^{2}$ \\
\hline Magnetization losses at $7.5 \mathrm{~V}$ peak square ${ }^{* *}$ & $8.23 \mathrm{~mW}$ \\
\hline Short circuit resistor at $100 \mathrm{kHz}^{* *}$ & $0.855 \Omega$ \\
\hline Cost/unit in larger quantity & 0.35 Euro \\
\hline
\end{tabular}

${ }^{*}$ Parameters from transformer catalogue. ${ }^{* *}$ Parameters measured from the lab.

ceramic capacitors to avoid electrolytic capacitors in the local supplies. The capacitor legs result in a frequency doubling effect in the supply ripple.

The characteristic of the common mode filter used as a transformer makes the power supply in (Figure 2(a)) very efficient. The insulation primary to secondary voltage is $2.4 \mathrm{kV}$, a good signal for a less-loss full transformer. Moreover, having a maximum current of $0.7 \mathrm{~A}$ and inductance of at least $1 \mathrm{mH}$ proves its good performance to supply the gate driver. In other words, this transformer uses very little magnetizing losses and needs a very low magnetizing current.

The half-bridge configuration ensures that there are no voltage spikes because of the leakage inductance and also no ringing. Both features are good compared to fly back converter designs. The series capacitors avoid a DC current 


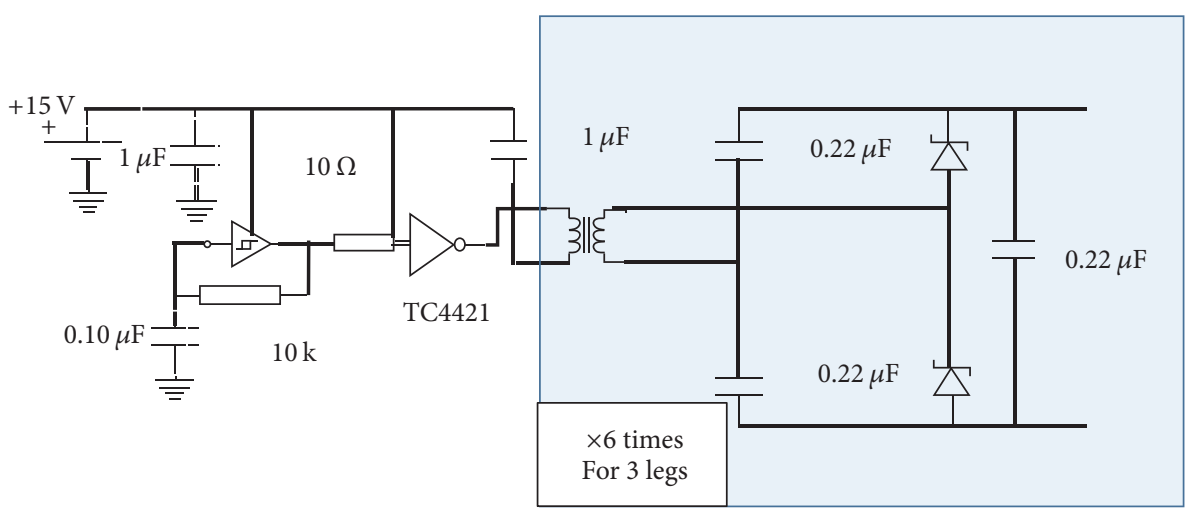

(a) MOSFET-IGBT less-conventional gate drive supply

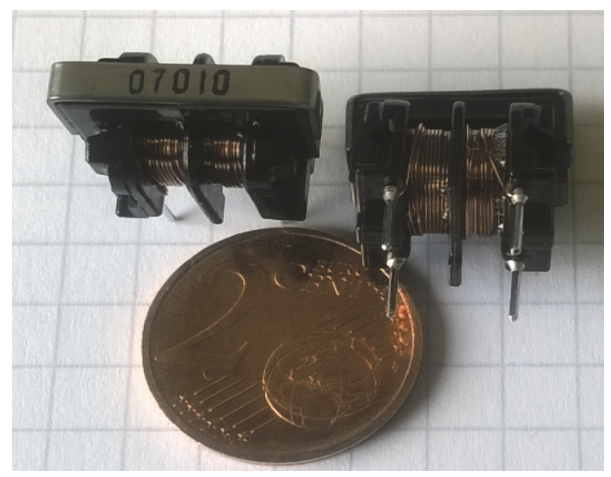

(b) Transformer (photo)

Figure 2

in the transformer and consequently the inductor does not saturate. This is due to the fact that $0.22 \mu \mathrm{F}$ at the secondary side is in series with $1 \mu \mathrm{F}$ on the primary side. A magnetizing loss of $8.23 \mathrm{~mW}$ fed with a square wave of $15 \mathrm{~V}$ peak-to-peak is observed. These losses are lower than expected. This might be caused by the high permeability ferrite of the common mode filter which is used at a low induction.

The total loss calculation considers mainly six transformers, TC4421 driver, and an optocoupler. More analytical analysis to evaluate the total losses of the power supply is made in the later section of the paper.

\section{MOSFET-IGBT Gate Drive Supply Analysis}

Figure 3 presents a block diagram of a half-bridge rectifier circuit. The figure has four major parts, the input voltage, the series inductor capacitor tank, the Schottky diode rectifier [18], and the output voltage. The output voltage is short circuit to the input to easily analyze the circulating current in the L-tank. The block diagram acts as a series LC converter. However, in the this simplified case, the capacitor is assumed to have an infinite value. Equation (1) and Figure 4 can be employed to evaluate the circulating current:

$$
\frac{d i}{d t}=\frac{V_{i}-V_{o}}{2 L_{s}} .
$$

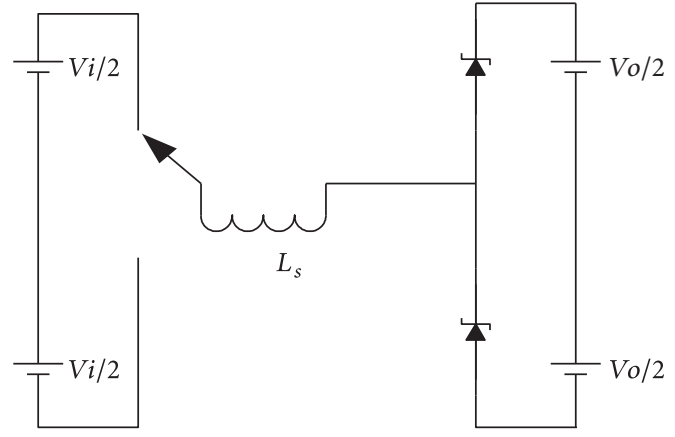

FIGURE 3: Half-bridge circuit [4].

Equation (1) expresses the current variation in the positive slope, Figure 4, and (2) explains the current variation in negative slope.

Here $V_{i}, V_{o}, I_{s}, I_{\text {out }}$, and $L_{s}$ are input voltage, output voltage, inductor current, output current, and series inductor, respectively.

$$
\frac{d i}{d t}=\frac{V_{i}+V_{o}}{2 L_{s}} .
$$

Combining (1) and (2) we obtain the following equation:

$$
\frac{T}{2}=\frac{2 L_{s} \times I_{s}}{V_{i}-V_{o}}+\frac{2 L_{s} \times I_{s}}{V_{i}+V_{o}} .
$$




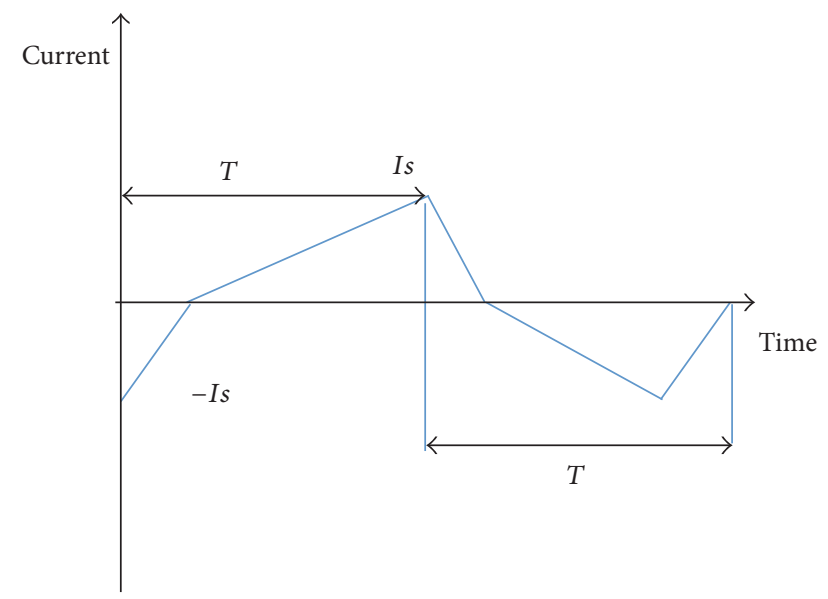

FIgURE 4: Current waveform in $L_{s}$ inductor [4].

Solving (3) for $I_{s}$ results in

$$
I_{s}=\frac{T \times L_{s} \times V_{i}}{8 \times\left(V_{i}^{2}-V_{o}^{2}\right)} .
$$

Hence, the DC output current is calculated as follows:

$$
I_{\text {out }}=\frac{T}{32} \frac{V_{i}^{2}-V_{o}^{2}}{L_{s} \times V_{i}} .
$$

Taking into account the fact that the impedance is pure inductor, the rectified current, $I_{\text {out }}$, can as well be evaluated using (5).

If a series LC impedance close to resonance (sine wave current) is considered, the fundamental voltage component of the output current, then, is

$$
I_{\text {out }}=\frac{2 V_{i}}{\pi^{2} Z_{\mathrm{LC}}} .
$$

Assuming that the impedance is pure inductance, hence the output currents result in

$$
I_{\text {out }}=\frac{2 V_{i}}{2 \pi^{3} f L_{s}} .
$$

Since $2 \pi^{3}=31.0$ is very close to 32 , then (5) can be corrected for the effect of a series capacitance above resonance frequency:

$$
I_{\text {out }} \approx \frac{T}{32} \frac{V_{i}^{2}-V_{o}^{2}}{L_{s} \times V_{i}}\left|\frac{j 2 \pi L s}{R r+j 2 \pi f L_{s}+1 / j 2 \pi f C_{s}}\right|,
$$

where $f=100 \mathrm{kHz} . R r$ is approximately $3 \mathrm{Ohms}$; however it does not influence much the result; the main voltage drop (compliance effect) is due to the leakage inductance. This approximation corresponds to simulations shown in the following section.

\section{MOSFET-IGBT Less-Conventional Gate Drive Supply Computer Simulation}

Figure 5 simulates the less-conventional gate drive supply shown in Figure 2. The simulation is done in MATLAB
TABLE 2: Voltage and current at different levels with $1 \mu \mathrm{F} \times 2$ of transformer primary side capacitor leg.

\begin{tabular}{lcc}
\hline Load $[\Omega]$ & Voltage $[\mathrm{V}]$ & Current $[\mathrm{mA}]$ \\
\hline $22 \mathrm{k}$ & 14.59 & 0.66 \\
$10 \mathrm{k}$ & 14.90 & 1.490 \\
$4 \mathrm{k} 7$ & 14.36 & 3.10 \\
$2 \mathrm{k} 2$ & 14.11 & 6.41 \\
$1 \mathrm{k}$ & 13.61 & 13.61 \\
$470 \mathrm{R}$ & 12.71 & 30.20 \\
$220 \mathrm{R}$ & 11.13 & 50.59 \\
$100 \mathrm{R}$ & 8.89 & 88.90 \\
$47 \mathrm{R}$ & 5.89 & 125.31 \\
$22 \mathrm{R}$ & 3.40 & 154.54 \\
$10 \mathrm{R}$ & 1.71 & 171.00 \\
\hline
\end{tabular}

Simulink $^{\mathrm{TM}}$ environment. The first block composed of a square wave DC source (TLC555) used as a Schmitt trigger and a driver TC4421 is replaced by a half-bridge converter in order to generate $+15 \mathrm{~V} \mathrm{DC}, 100 \mathrm{kHz}$ power supply. Parameters from Table 1 are used to simulate the transformer. From the simulation, some voltage and current characteristics at different levels, low and heavy, of the load are presented.

Taking into account the fact that the resistor varies during the turn-on and turn-off of a power switch device [17], the simulation considers the current during short circuit and during full load.

Figures 6 and 7 show that the power supply pulls down the voltage and the current to low values when $R_{\text {load }}$ becomes close to the short circuit. The consumed power is $3.3 \mathrm{~mW}$. When the load becomes $10 e 3 \mathrm{Ohms}$, the output voltage is 13.2 V DC as shown in Figure 8.

A control circuitry that provides undervoltage lockout (ULVO) protection must have a voltage lower than $13 \mathrm{~V} \mathrm{DC.}$ The saturation protection has also to take into consideration the output voltage level of the power supply. The scenarios present as well the fact that the standby power of the supply is $3.294 \mathrm{~mW}$.

\section{MOSFET-IGBT Less-Conventional Gate Drive Supply Lab Experiments}

Some lab experiments were conducted in order to evaluate the power consumption of the gate driver supply. Figure 8 shows the output current and input and output voltage while the supply is lowly loaded with a $10 \mathrm{k} \Omega$ resistor. Two boundaries in Figures 7 and 8 reveal the undervoltage lockout (ULVO) specifications which must be used for the gate driver. Some measurements taken during the lab experiment are shown in Table 2.

The local supply characteristic in Figure 9 allows the supply to drive quite large IGBTs at high frequencies. It is necessary to point out that the characteristic can be made less compliant when a smaller series capacitor leg (closer to the series resonance) is used. The risk is that the short circuit notice capability feature of the supply can be lost. However, the current absorbed by the square wave driver can 


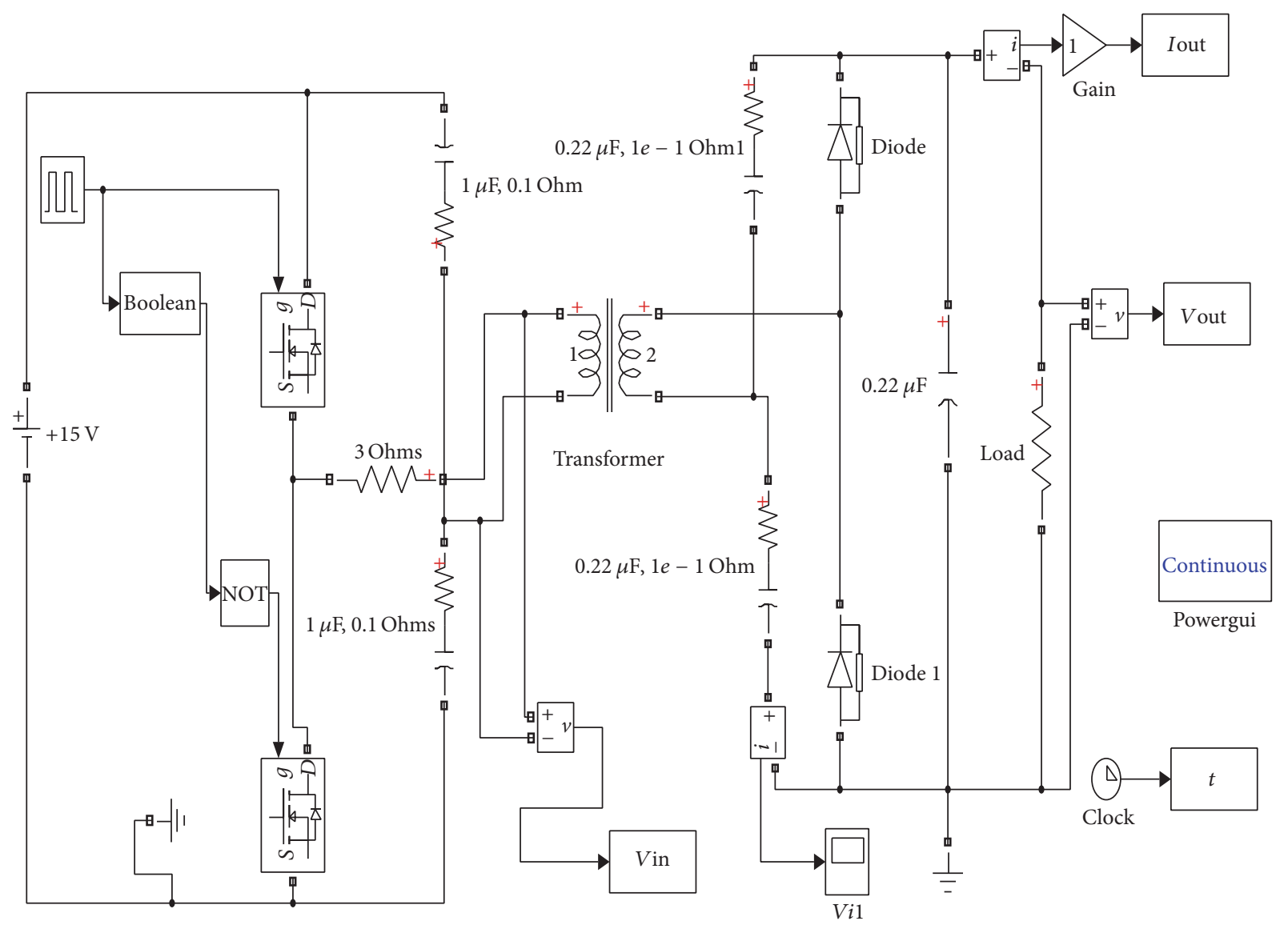

FIGURE 5: MOSFET-IGBT gate drive supply MATLAB simulation.

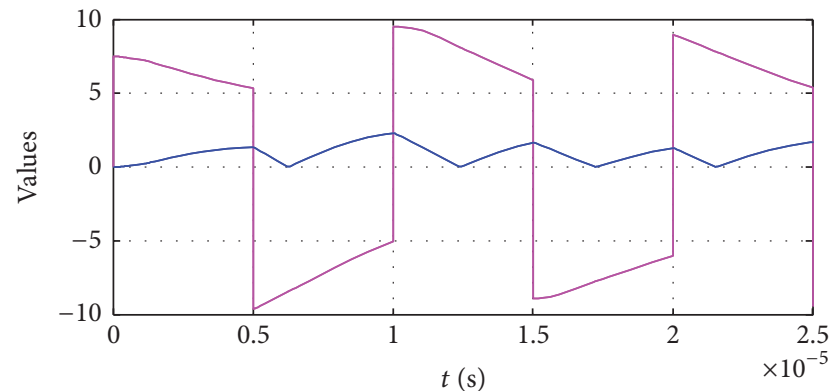

- Vin $[\mathrm{A}]$
Iout $[\mathrm{V}]$

FIGURE 6: Transformer input current, $I_{p 1}$, and output current, Iout at $R_{\text {load }}=0.1 \Omega$.

be monitored in order to shut down the driver if an overload is, short circuit proof, observed. A desaturation protection pulling down the local supply can be designed. It can use the output current and voltage characteristics shown in Figure 9.

Figures 10 and 11 show the input and output voltage when the supply is lowly loaded with $1 \mathrm{k} \Omega$ resistor and when the supply is loaded with $10 \mathrm{k} \Omega$ resistor. Similar to the simulation, Figures 10 and 11 show two operating boundaries of the local gate driver supply, the undervoltage lockout (ULVO)

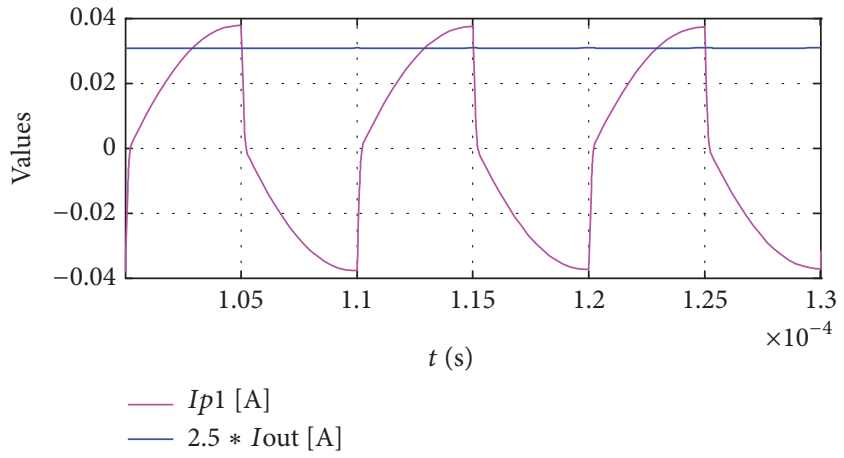

FIGURE 7: Transformer primary input current, $I_{p 1}$, and output current at $R_{\text {load }}=1 e 3 \Omega$.

and the desaturation protection. The undervoltage lockout (ULVO) must be lower than $12 \mathrm{~V}$ in order to switch off the power switch devices safely. Table 3 shows the voltage drop for three different cases. The voltage drop was measured by inserting a resistor of $10 \Omega$ at the input of power supply. The single transformer draws $0.26 \mathrm{~mA}$ at $100 \mathrm{kHz}$. Table 4 shows the consumption of four most important areas of the gate supply. The transformer consumes less compared to the driver, TC4421, and TLC 555. It is obvious that to use one 
TABLE 3: Voltage drop with 1 transformer compared to 6 transformers.

\begin{tabular}{lcc}
\hline Capacitors on primary leg & Number of transformers & Voltage drop [mV] \\
\hline $100 \mu \mathrm{F}$ (electrolytic type) with $10 \Omega$, local supply load & 6 & 990 \\
& 1 & 917 \\
$1 \mu \mathrm{F} \times 2$ (film type) with local supply open load & 6 & 664 \\
$1 \mu \mathrm{F} \times 2$ (film type) with local supply open load & 1 & 579 \\
\end{tabular}

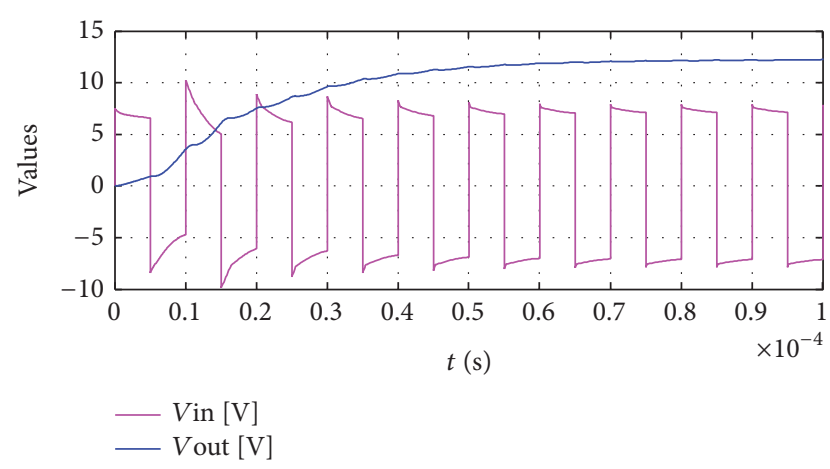

FIGURE 8: Transformer input, $V$ in, and output voltage, $V$ out, at $R_{\text {load }}$ $=1 e 3 \Omega$.

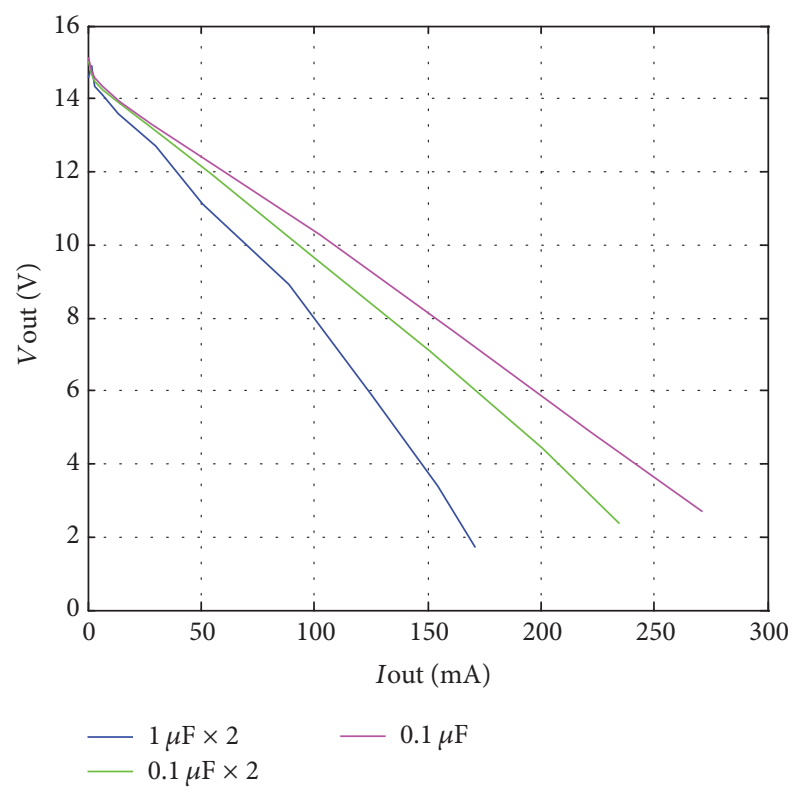

FIGURE 9: Output current and voltage at different capacitor values.

driver at primary side instead of using six at secondary side gives an advantage to topology in Figure 2(a).

In fact, the six transformers are preferred on the secondary side of the gate driver power supply. The no-load consumption of a transformer has been verified while tying 6 transformers compared to one and dividing the current consumption by 5 . The authors were surprised by the very low value and checked the result several times. The no load of the transformer is much lower than the driver and the
TABLE 4: Gate driver supply consumption at no load.

\begin{tabular}{lc}
\hline Area & Amount $[\mathrm{mA}]$ \\
\hline Transformer & 0.26 \\
TC 4421 & 5.310 \\
TLC 555 & 1.75 \\
Feedback, 10K & 0.75 \\
Sum & 8.07 \\
Actual measured sum & 15 \\
\hline
\end{tabular}

used square wave generator. Hence, it is practically good to use a single square wave generator and multiple transformer loads. At no load, the power consumption is $15 \mathrm{~mA} * 15 \mathrm{~V}=$ $0.225 \mathrm{~W}$, whereas, at full load, by neglecting internal gate driver capacitance, the consumption power is $45 \mathrm{~mA} * 15=$ $0.675 \mathrm{~W}$. The injected current in the reference of the power supply of the controller is Ctotal $* d V / d t$, Ctotal $=C$ optocoupler drive $+C$ transformer, and $C$ total is about $4 \mathrm{pF}$. Then, at $d V / d t$ of $20 \mathrm{~V} / \mathrm{ns}$ and $4 \mathrm{pF}$ it injects an $80 \mathrm{~mA}$ spike in the controller reference. This is due to the fact that the design has the desaturation protection where the transformer can also detect the desaturation; hence a second optocoupler is not needed in the gate driver topology. This avoids a second $2 \mathrm{pF}$ optocoupler capacitance. If a transformer of $10 \mathrm{pF}$ is used as well as two optocouplers Ctotal could be $14 \mathrm{pF}$. This corresponds to a $280 \mathrm{~mA}$ spike which means 3.5 times larger compared to the present design. So, it is obvious that lowering the transformer capacitance can reduce the EMC problem in the converter.

The total gate drive circuit can be operated below $150 \mathrm{~mW}$ consumption. If the control is not required at all the enabling of the TLC555 could be used to shut down the supplies completely.

Figure 12 shows the transformer primary current wave form when the infinite capacitor of $100 \mu \mathrm{F}$ is on primary leg. The current wave form proves that the impedance of the transformer is pure inductance. Using an electrolytic capacitor can influence the frequency to be closer to the resonance frequency of the gate driver supply.

\section{Conclusion}

The paper showed that the less-conventional gate drive local power supply can meet the required parameters for the better performance even if 6 separated transformers are used in the design. The compliant supply has some impedance 


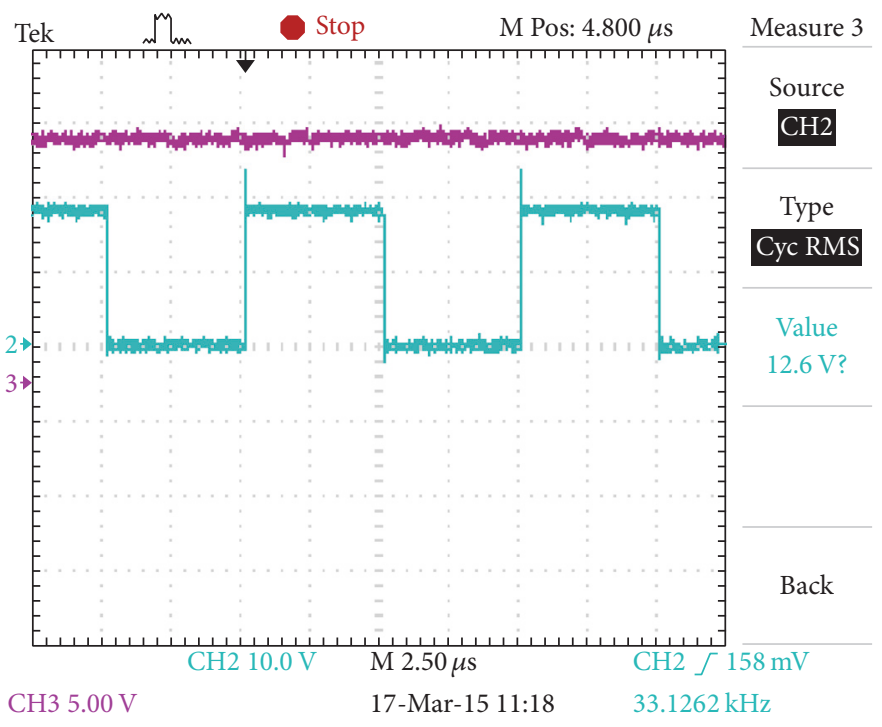

FIGURE 10: Input voltage and output current at $R_{\text {load }}=10 e 3 \Omega$.

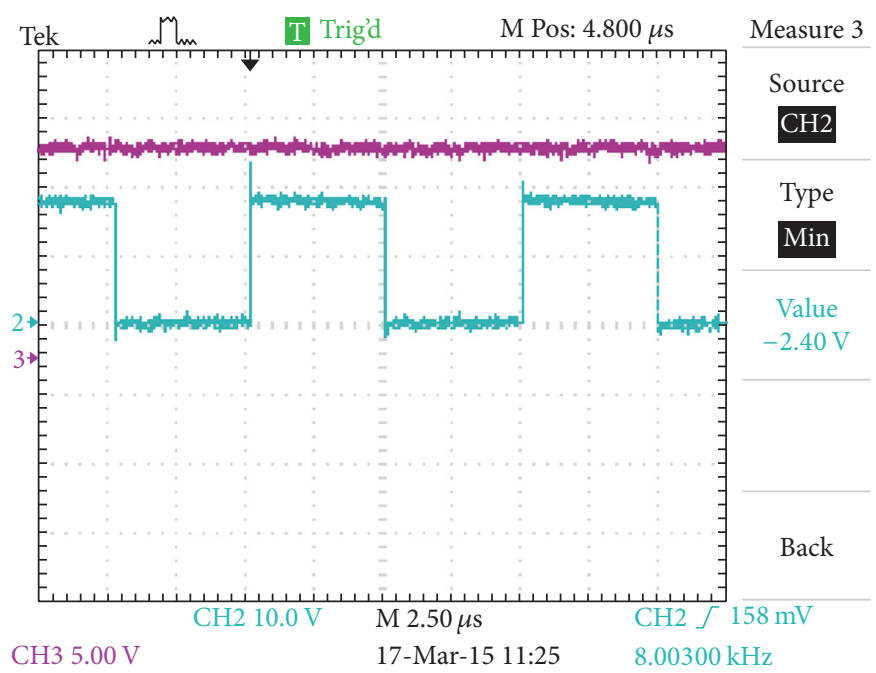

FIGURE 11: Input voltage and output current at $R_{\text {load }}=1 e 3 \Omega$.

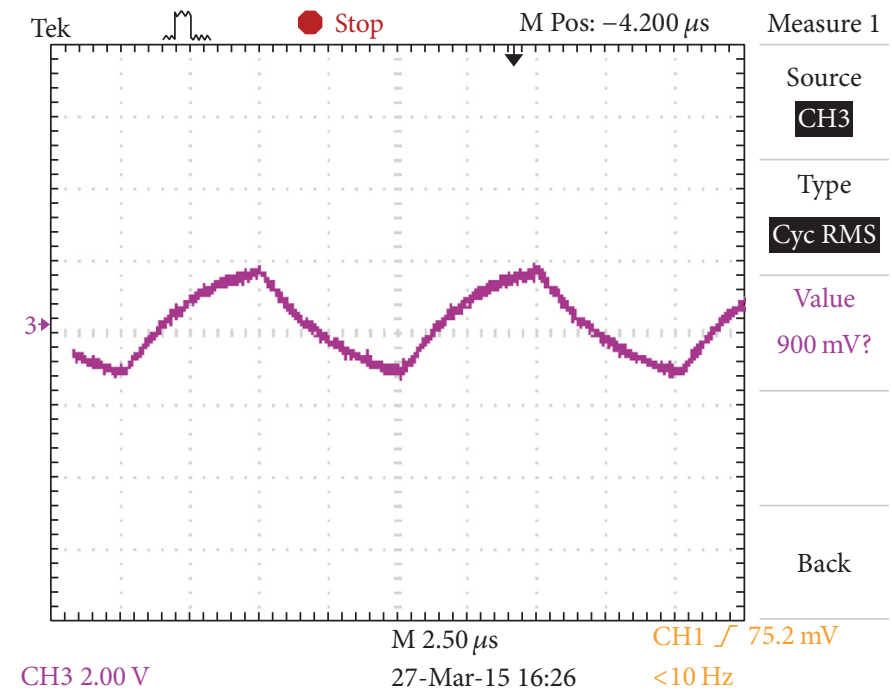

FIGURE 12: Transformer primary loaded current wave form with $100 \mu \mathrm{F}$ (electrolytic capacitor on primary leg), $R_{\text {load }}=10 \Omega$. 
but it is short circuit proof. It is made while hacking a common mode type filter as a transformer, as it shows a good insulation and a very low parasitic capacitance between primary and secondary coils. The transformer is also costeffectively competitive and it has low losses. A half-bridge series resonating converter working at high frequency above the resonance can be used with superior performance in a gate drive power supply. The proposed solution is valuable for converters where galvanic separation and low standby power are needed.

\section{Conflicts of Interest}

The authors declare no conflicts of interest.

\section{References}

[1] S. Brehaut and F. Costa, "Gate driving of high power IGBT through a Double Galvanic Insulation Transformer," in Proceedings of the 32nd Annual Conference on IEEE Industrial Electronics (IECON '06), pp. 2505-2510, IEEE, November 2006.

[2] T. Ying, W.-H. Ki, and M. Chan, "Area-efficient CMOS charge pumps for LCD drivers," IEEE Journal of Solid-State Circuits, vol. 38, no. 10, pp. 1721-1725, 2003.

[3] G. F. W. Khoo, D. R. H. Carter, and R. A. Mahon, "Comparison of charge pump circuits for half-bridge inverters," IEE Proceedings: Circuits, Devices and Systems, vol. 147, no. 6, pp. 356-362, 2000 .

[4] Z. H. Hsieh, N. X. Huang, M. S. Shiau, H. C. Wu, S.-Y. Yang, and D. G. Liu, "A novel mixed-structure design for highefficiency charge pump," in Proceedings of the 16th International Conference on Mixed Design of Integrated Circuits and Systems", Lodz, Poland, June 2009.

[5] R. L. Lin and F. C. Lee, "Single-power-supply-based transformerless igbtmosfet gate driver with $100 \%$ high-side turn-on duty cycle operation performance using auxiliary bootstrapped charge pumper," IEEE Journal, vol. 2, pp. 1205-1209, 1997.

[6] S. Zeltner, "Insulating IGBT driver with PCB integrated capacitive coupling elements," in Proceedings of the IEEE, Nuremberg, Germany, March 2010.

[7] C. Klumpner and N. Shattock, "A cost-Effective solution to power the gate drivers of multilevel inverters using the bootstrap power supply technique," in Proceedings of the 24th Annual IEEE Applied Power Electronics Conference and Exposition, (APEC '09), pp. 1773-1779, IEEE, February 2009.

[8] M. Akahane, A. Jonishi, M. Yamaji et al., "A new level up shifter for HVICs with high noise tolerance," in Proceedings of the 7th International Power Electronics Conference, IPEC-Hiroshima ECCE Asia '14, pp. 2302-2309, IEEE Journal, May 2014.

[9] B. Basavaraja and D. V. S. S. S. Sarma, "Application problem of PWM AC drives due to long cable length and high dv/dt," in Proceedings of the 2006 International Conference on Power Electronics, Drives and Energy Systems, (PEDES '06), pp. 1-6, IEEE, December 2006.

[10] J. Andreu, J. M. De Diego, I. M. de Alegria, I. Kortabarria, J. L. Martin, and S. Ceballos, "New protection circuit for highspeed switching and start-up of a practical matrix converter," IEEE Transactions on Industrial Electronics, vol. 55, no. 8, pp. 3100-3114, 2008.
[11] A. Dartigues, B. Giffard, R. Perret, and C. Schaffer, "Driver integration in monolithic MBS (MOS bidirectional switch): perturbations in the off-state," IEEE, vol. 5, pp. 3003-3009, 2000.

[12] http://www.farnell.com/datasheets/1760497.pdf.

[13] http://ww1.microchip.com/downloads/en/DeviceDoc/F.pdf.

[14] A. Kadavelugu and S. Bhattacharya, "Design considerations and development of gate driver for $15 \mathrm{kV}$ SiC IGBT," in Proceedings of the 29th Annual IEEE Applied Power Electronics Conference and Exposition, APEC '14), pp. 1494-1501, March 2014.

[15] W. Huai, M. Liserre, F. Blaabjerg et al., "Transitioning to physics-of-failure as a reliability driver in power electronics," IEEE Journal of Emerging and Selected Topics in Power Electronics, vol. 2, no. 1, pp. 97-114, 2014.

[16] A. Van den Bossche, A. Marnov, and A. Valchev, "Transistor desaturation protection using the driver undervoltage lock out," in Proceedings of the Internationale Genie Electrique Conference (CIGE '08), pp. 1-4, Béchar, Algeria, October 2008.

[17] B. Zhao, H. Qin, X. Nie, and Y. Yan, "Evaluation of isolated gate driver for SiC MOSFETs," in Proceedings of the 2013 IEEE 8th Conference on Industrial Electronics and Applications, (ICIEA '13), pp. 1208-1212, June 2013.

[18] http://www.alldatasheet.com/datasheet-pdf/pdf/396089/INFINEON/BAS3007A-RPP.html. 


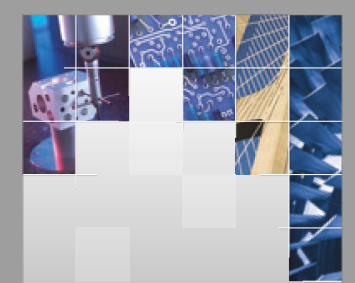

\section{Enfincering}
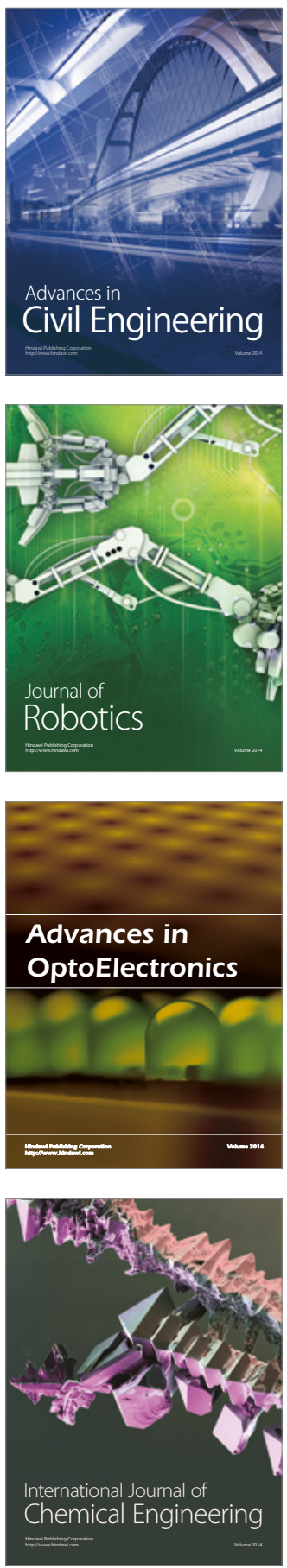

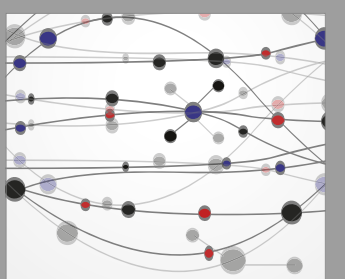

The Scientific World Journal

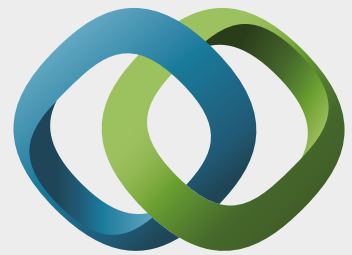

\section{Hindawi}

Submit your manuscripts at

https://www.hindawi.com
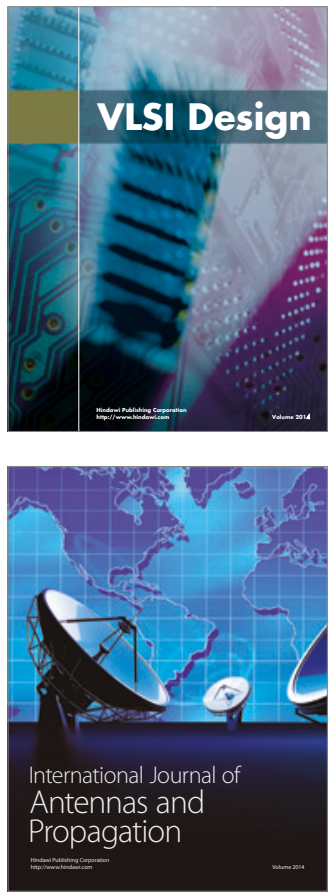

\section{Rotating}

Machinery
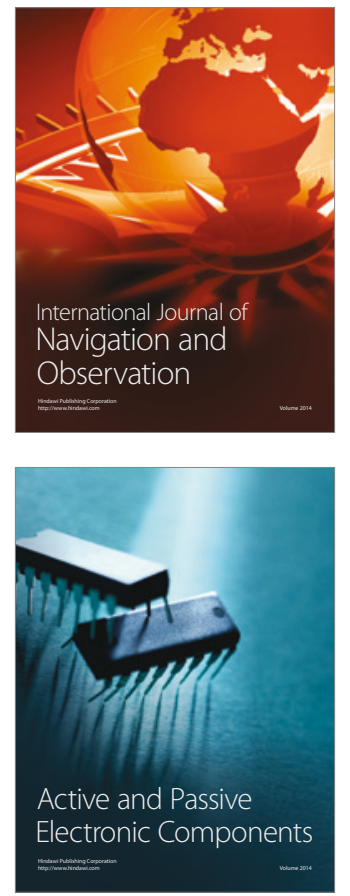
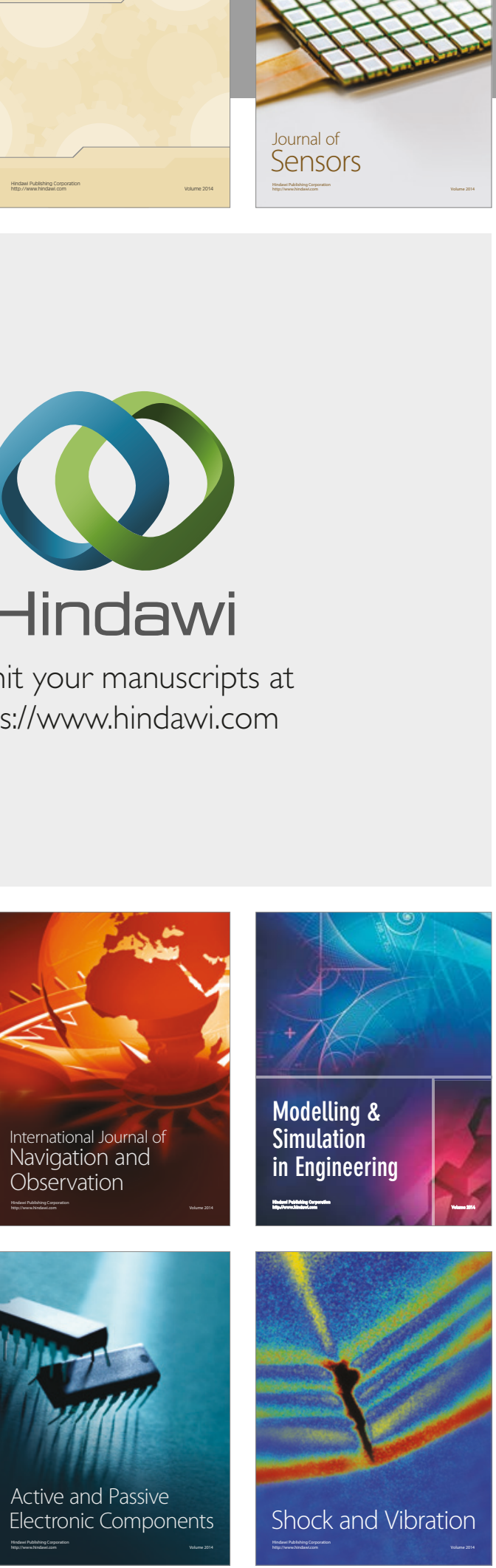
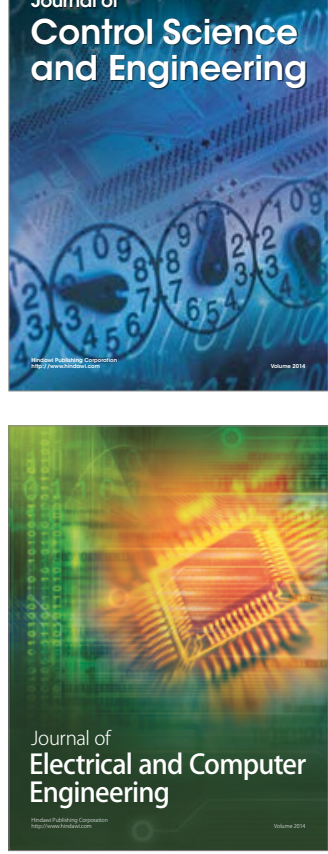

Distributed

Journal of

Control Science

and Engineering
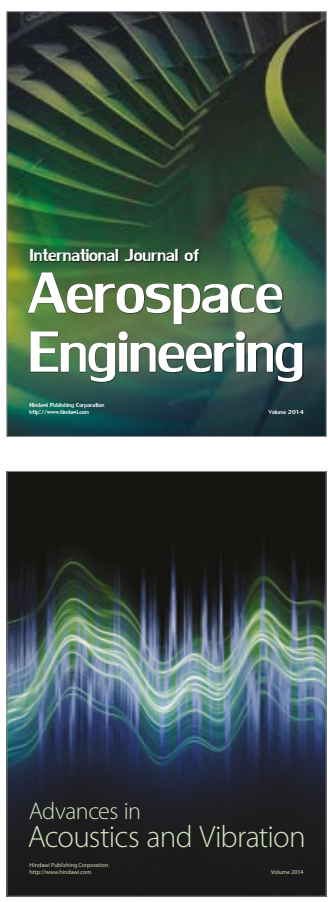

Sensor Networks 